\title{
Doing Nothing: Adults With Disabilities With No Daily Activities and Their Siblings
}

\author{
Julie Lounds Taylor \\ Vanderbilt Kennedy Center, Vanderbilt University; and Vanderbilt University School of Medicine and \\ the Monroe Carell Jr. Children's Hospital at Vanderbilt University
}

Robert M. Hodapp

Vanderbilt Kennedy Center, Vanderbilt University; and Peabody College, Vanderbilt University

\begin{abstract}
A significant concern of parents and professionals is that adults with intellectual and developmental disabilities will go without regular educational-vocational activities. The authors examined predictors of such inactivity in individuals with intellectual and developmental disabilities, as well as how inactivity related to their sibling's well-being and the sibling relationship. Participants included 796 siblings of adults with intellectual and developmental disabilities who responded to a web-based survey. Nearly $13 \%$ of adults with intellectual and developmental disabilities were without daytime activities; these adults had more emotional-behavioral and health problems, were more underserved by the formal service system, and had parents who were less able to provide care. Although siblings of adults without activities reported more depressive symptoms, worse health, and less close sibling relationships, inactivity no longer predicted these problems after controlling for characteristics that predisposed adults with intellectual and developmental disabilities to have no activities.
\end{abstract}

Whether it be working, volunteering, or going to school, the performance of activities on a regular basis seems characteristic of a fulfilling adult life. For many decades, researchers have extolled regular employment as a way to provide adults structure, purpose, and focus (McKee-Ryan, Song, Wanberg, \& Kanicki, 2005; Winkelmann \& Winkelmann, 1998). Conversely, being laid off or fired from one's job is generally perceived as a major psychological blow, placing adults at increased risks for a host of personal and familial problems (Eliason \& Storrie, 2009; Eriksson, Agerbo, Mortensen, \& Wesergaard-Nielson, 2010; Hansen, 2005).

Similar issues arise for adults with intellectual and developmental disabilities. In a study examining life success for British children with Down syndrome, Shepperdson (1995) found that environmental stimulation during childhood and adolescence was the best predictor of adult intellectual and adaptive outcomes. Conversely, from clinical findings, those "young adults who had limited or no programming after high school, or were alone during parts of the day, were at higher risk for disorganized thinking or mood" (Dykens, 2007, p. 276). Like adults in the general population, individuals with intellectual and developmental disabilities require activities and stimulation to feel fulfilled.

Unfortunately, compared with other adults, adults with disabilities more often experience prolonged inactivity. As estimated from the $\mathrm{Na}-$ tional Longitudinal Transition Study-2 (Wagner, Newman, Cameto, Garza, \& Levine, 2005), inactivity after leaving high school was experienced by approximately $20 \%$ of persons with a variety of disabilities, with other studies reporting unemployment-inactivity rates ranging from 10\% (Farley 
et al., 2009) to over 40\% (Blackorby \& Wagner, 1996; Keogh, Bernheimer, \& Guthrie, 2004). Individuals were at highest risk for inactivity when they had autism, intellectual disabilities, orthopedic impairments, or multiple disabilities (Wagner et al., 2005). With $60 \%$ of adults with intellectual and developmental disabilities living at home with their parents (Braddock, Hemp, \& Rizzolo, 2008), a disturbing picture emerges: Many adults with intellectual and developmental disabilities live in the family home, do not work or engage in productive activities, and suffer as a result.

Despite such high risks for inactivity, only a few studies have determined which persons with intellectual and developmental disabilities are most at risk, particularly across the adult years. But from these few studies, three types of predictors seem evident. First, inactivity during adulthood seems related to several personal characteristics. Thus, increased percentages of individuals with disabilities experienced unemployment or no activities when they had higher levels of behavior problems (Howlin, Mawhood, \& Rutter, 2000), had autism, and did not have Down syndrome (Esbensen, Bishop, Seltzer, Greenberg, \& Taylor, 2010). Inactivity may also relate to level of functioning. Although some studies have reported that lower functioning individuals more often experience no activities (Keogh et al., 2004), others have found that, for individuals with autism spectrum disorder, risks increase for higher functioning individuals (Taylor \& Seltzer, 2010; 2011). Females (vs. males) with various types of disabilities may also be less often encouraged in their vocational aspirations (Powers, Hogansen, Geenen, Powers, \& Gil-Kashiwabara, 2008).

Second, characteristics of the adult service system may be important. In most American states, service systems are stretched to the limit, with increasing numbers of adults receiving stable or decreasing amounts of adult service resources (Prouty, Smith, \& Lakin, 2006). The United States is not alone in this regard; as Emerson, Fujiura, and Hatton (2007) noted, "Two features of developmental-disabilities supports and infrastructure are common to all countries: Availability and access is inadequate, and reliable information on the status and prospects of citizens with developmental disabilities is extremely limited or not available" (p. 600). As a result, denial of services and waiting lists are common, and many adults with intellectual and developmental disabilities experience multiple areas in which they need, but do not receive, formal services.

Third, percentages of inactive adults may relate to characteristics of their families and other informal support systems. Taylor and Seltzer (2011) found that greater percentages of those adults with autism spectrum disorder who were unemployed lived with their parents in the family home. As these adults age, whether the individual is inactive might also relate to the degree to which parents are able to care for them and can help their offspring receive adult services (Caldwell, 2006; Heller \& Schindler, 2009). Sibling gender may also be important, because female siblings are most likely to become caregivers of their adult brothers and sisters with intellectual and developmental disabilities (Orsmond \& Seltzer, 2000). Furthermore, siblings who live closer to their brother or sister may be more able to help.

An additional, related question concerns the effects on others when adults with intellectual and developmental disabilities do not perform any daily activities. If, in most cases adult siblings will assume long-term care for their brother or sister with intellectual and developmental disabilities (Hodapp, Glidden, \& Kaiser, 2005), the inactivity of the family member with disabilities becomes a family affair. What are the effects on others when the adult with intellectual and developmental disabilities is unemployed and inactive, especially on the family's adult siblings? How do these siblings fare in terms of their well-being, health, and depression?

In the present study, we used a national sample of siblings of adults with intellectual and developmental disabilities to answer two questions. First, which predictors put adults with intellectual and developmental disabilities at risk for having no vocational or educational activities? We hypothesized that the likelihood that adults with intellectual and developmental disabilities would have no activities might increase when the adult also had an autism diagnosis, more difficult emotional and physical health problems, more unmet service needs, and fewer family-informal resources. Second, does the lack of vocationaleducational activities for their brother or sister with intellectual and developmental disabilities relate to the well-being of adult siblings? The absence of activities for their brother or sister with intellectual and developmental disabilities might relate to lower levels of well-being of the adult sibling and a less close sibling relationship. 


\section{Method}

\section{Participants}

Participants included 796 adult siblings of individuals with disabilities. Siblings were predominantly female $(80.2 \%)$, White $(91.1 \%)$, well educated $(76.6 \%$ completed at least a bachelor's degree), and married (58.3\%). The median income for siblings was just under $\$ 50,000$ per year (median $=\$ 49,556.00)$. Sibling respondents ranged from 18 through 85 years of age $(M=$ $40.81, S D=12.87$ ), with 100 or more respondents at every 10 -year age span, from the 20 s through the 50s. The sample resided in all 50 states plus the District of Columbia, with 23 states featuring 10 or more respondents.

Adult brothers or sisters with intellectual and developmental disabilities were predominantly male $(57.4 \%)$, and ranged in age from 22 to 81 years ( $\geq 100$ brothers/sisters were each in their $20 \mathrm{~s}, 30 \mathrm{~s}, 40 \mathrm{~s}$, and $50 \mathrm{~s}$, respectively), with a mean age of 39.48 years $(S D=12.02)$. Commonly reported disabilities included intellectual disabilities $(n=469 ; 58.9 \%)$, Down syndrome $(n=210$; $26.4 \%)$, cerebral palsy $(n=111 ; 13.9 \%)$, autism $(n$ $=97 ; 12.2 \%)$, sensory impairment $(n=46 ; 5.8 \%)$, and unspecified developmental disability $(n=37$; 4.6\%). Note that percentages do not add to $100 \%$ because more than a single category could be indicated. Of these brothers/sisters with intellectual and developmental disabilities, 43.7\% lived in their parents' or relatives' homes $(6.0 \%$ with the respondent sibling), with the remaining living in group homes $(23.4 \%)$, by themselves or with spouse-significant other-friend (11.5\%), in supervised apartments $(10.3 \%)$, or in larger facilities, residential schools, or other residences (11.1\%).

This study's 796 participants constituted a subset of 1,166 adult siblings of individuals with intellectual and developmental disabilities who answered a national, web-based survey of sibling characteristics, functioning, and relationships (Hodapp, Urbano, \& Burke, 2010). Due to the study's focus on only those siblings whose brothers or sisters were also adults, we excluded 274 respondents whose brother/sister with intellectual and developmental disabilities was younger than 22 years old. We also excluded siblings who did not indicate that they had a brother or sister with intellectual or developmental disabilities (i.e., indicating that their brother or sister had only chronic health problems; $n=95$ ). Last, 1 additional respondent was dropped because he or she did not answer the vocational and educational activities questions, resulting in a final sample of 796 siblings.

\section{Procedures}

Survey development and participant recruitment. In collaboration with the National Sibling Consortium, a small group of sibling researchers (see Acknowledgments), the questionnaire was developed and revised. On revision, the questionnaire and the study itself were approved by the institutional review board (IRB) at Vanderbilt University and presented to the Board of Directors of The Arc. The completed, approved questionnaire was then put up onto a secure web site of Vanderbilt University. As survey responses accumulated, the Survey Gold program (Golden Hills Software, Inc., 2011) was used to store survey responses, which were downloaded periodically into SPSS-analysis data sets to guard against computer malfunctions.

Recruitment of potential participants was timed to coincide with the finalization of the web-based survey. Beginning in late February 2006, news of the survey was disseminated through The Arc's electronic mailing lists and other computer-based information dissemination networks, and a short article about the survey appeared in InSight, the national newsletter of The Arc, in early May. News of the survey was also disseminated through the web site of the Association of University Centers on Disability (AUCD; 2011), Sibnet network (Meyer, n.d.), and several state developmental disability networks and newsletters.

Although we received the majority of responses electronically, respondents could also fill out and return to us paper versions of the survey. In all newsletter and web-based advertisements, potential respondents were informed that they could either call us at a toll-free answering machine or e-mail us (e-mail requesters could receive either a mailed paper version or a Microsoft Word document attached to the return e-mail). Responding to both phone and e-mail requests, we mailed (in self-addressed, stamped envelopes) over 100 paper surveys to individual siblings and 250 to several professionals who ran sibling workshops or had access to families without high-speed Internet access. From these mailings, we received approximately 80 paperbased responses, which a research assistant entered into the web site. 
The Adult Sibling Survey (described below) took approximately $20-25 \mathrm{~min}$ to fill out. On going to the address of the web site, respondents first saw a screen describing the study. After agreeing to participate, the respondent was then directed to the second screen, which contained a brief description of the survey and the survey itself. On completion of the survey, the respondent was thanked and answered that they had completed the survey. By pushing the completion button, the survey was submitted to the web site. At this point, a third screen appeared, and respondents were asked whether they wanted to participate in future family research studies or to receive a summary of the questionnaire results. If so, respondents were then asked to fill out their name, address, phone number, and e-mail address.

Throughout this process, all responses remained anonymous. Consistent with our IRB approval to perform an anonymous, web-based survey, we kept all three windows separate. Even those individuals who, in the third window, registered their names and contact information were not linked to their earlier responses. Similarly, those respondents who answered via regular mail sent in envelopes in which both the address and return address were directed to our research mailbox; after their questionnaires arrived, their responses were entered via computer. None of the individual responses were linked to identified individuals.

Adult Sibling Questionnaire. Specifically designed for this study, the Adult Sibling Questionnaire comprised 163 questions divided into eight distinct sections. Except for the final section, responses generally involved clicking "yes" to one of the question's options, which involved responses that were either categorical (e.g., gender) or on a Likert-type scale. Certain questions were borrowed from existing short-form measures; these are indicated in the appropriate sections. The eight sections included information on the respondent (gender, age, ethnicity, educational level), the brother or sister with disabilities (type of disability, age, living arrangement, daily activities, and employment), parents and family of origin (birth order of respondent and brother/ sister), joint activities and involvement (number of hours per month the respondent was in contact with brother/sister, type of contact), transitions experienced over the past 12 months (divorce, death, change in residence), sibling relationship (the degree of sibling closeness), respondent's future caregiving, and respondent health and depression.

\section{Measures}

Dependent and independent variables differed based on the specific questions of interest in the two parts of this study. In Part 1, we examined variables that were associated with whether the brother or sister with intellectual and developmental disabilities experienced no daily activities. The independent variables in Part 1 included factors that might contribute to his/her inactivity, such as characteristics of the adult with intellectual and developmental disabilities, formal supports, and family-informal supports. In Part 2, we examined the relations between this inactivity and the sibling's well-being, health, as well as the sibling relationship.

\section{Part 1: Predictors of Lack of Activity}

Dependent variable. To determine whether the brother/sister with intellectual and developmental disabilities engaged in no daily activities, respondents answered the following question: "Which of the following best describes your brother or sister with disabilities' daily work or activities? (Check all that apply.)" One or more of the following nine responses could be checked: "works in paid job within the community"; "works in paid job with some assistance (e.g., a job coach)"; "works in a paid job, with modifications"; "supervised workshop"; "in school or training for future job"; "volunteer activities"; "prevocational setting"; "activity setting/day program"; or "does not work or has no activity setting". Those respondents who checked that their brother/sister did not work or have any activity setting were considered to comprise the "no activity" group; all others were considered to have some employment or activities.

Independent variables. Characteristics of the brother or sister with intellectual and developmental disabilities. Characteristics of the brother or sister with intellectual and developmental disabilities included his or her age, gender $(0=$ male, $1=$ female $)$, diagnosis, health issues, emotional-behavioral problems, and functional abilities. Diagnosis was determined by whether the respondent answered that their brother/sister with disabilities had one or more of the following: intellectual disabilities, Down 
syndrome, fragile X syndrome, Prader-Willi syndrome, autism, emotional disturbance or condition, sensory impairment, cerebral palsy, Williams syndrome, and unspecified developmental disability. Siblings rated the current physical health problems and emotional-behavioral problems of their brother or sister with intellectual and developmental disabilities on a scale ranging from $1=$ not a problem to $5=$ very much a problem. The measure of functional abilities of the brother/ sister comprised 15 items from the Activities of Daily Living Scale (ADL: Seltzer \& Li, 1996). Items included the degree to which the brother/ sister with disabilities was able to walk, run errands, read, and prepare meals $(1=$ not at all to $5=$ very well). Variables were then summed into a single, cumulative score, ranging from 15 to 75 , with higher scores indicating more functional independence. This scale has been used to provide an estimate of functional abilities of individuals with disabilities (Seltzer \& Li, 1996).

Characteristics of formal and family-informal support. Formal supports were examined in terms of the number of services received by the brother/sister with intellectual and developmental disabilities, as well as the number of services that were needed but not being received ("unmet service needs"). Sixteen potential services were listed, including case management, respite care, transportation, physical therapy, and speech therapy. The following family-informal supports were examined: residential status $(0=$ living outside of parental home; 1 = living inside of parental home); the degree to which both parents were judged as being able to care for the brother/sister with disabilities $(0=$ both parents are deceased; $1=$ poor; 2 = fair; $3=$ moderate; $4=$ good $; 5=$ excellent $)$; gender of the sibling respondent $(0=$ male, 1 = female), whether the respondent was the sole other (i.e., nondisabled) sibling $(0=$ sole nondisabled sibling; $1=$ other siblings in family); and the distance (in traveling time) that the sibling lives from their brother/sister with disabilities (from $1=$ less than 15 minutes to $4=$ more than 60 minutes).

\section{Part 2: Sibling Well-Being, Health, and the Sibling Relationship \\ Dependent variables. Because the focus of} Part 2 was on how the brother's/sister's inactivity might relate to sibling functioning and relationships, we examined measures of well-being, health, and the sibling relationship. Sibling wellbeing was measured by positive well-being and depressive symptoms. Positive well-being was assessed using a modified version of Ryff's Psychological Well-Being Measures (Ryff, 1989), which consists of 18 statements, such as, "I judge myself by what I think is important, not by the values of what others think is important," and "I have not experienced many warm and trusting relationships with others." The participants responded to each statement on a scale of 1 (strongly disagree) to 6 (strongly agree). Items were summed to form an overall positive well-being score reflecting six dimensions of well-being: selfacceptance, positive relations with others, autonomy, environmental mastery, purpose in life, and personal growth (Cronbach's $\alpha$ in this sample $=$ .85). Respondents were also asked to rate symptoms of depression felt in the last week (5 questions from the Center for Epidemiological Studies Depression Scale [CES-D]; Radloff, 1977). For the respondents of this study, Cronbach's alpha for the depressive symptoms items equaled .79 .

Siblings reported their own health on a 5point scale $(1=$ poor to $5=$ excellent $)$; this measure of self-rated health has been found to be a strong predictor of lifespan (Idler \& Benjamini, 1997). These measures of perceived health and depressive symptoms have previously been used in studies of families of children with disabilities (Greenberg, Seltzer, Krauss, Chou, \& Hong, 2004; Hodapp et al., 2010).

The sibling relationship was measured by affective closeness and the amount of time spent with the brother or sister with intellectual and developmental disabilities. Affective closeness was derived from the Positive Affect Index of relationship quality (Bengston \& Black, 1973), in which respondents rated their relationship with their brother or sister with intellectual and developmental disabilities on the following dimensions: understanding, trust, fairness, respect, affection, and closeness. Responses for each item range from $1=$ not at all to $6=$ extremely (Cronbach's $\alpha=.92$ ). The responses were summed into an overall score ranging from 6 to 36 , with higher scores indicating a closer sibling relationship. Siblings were also asked the amount of time that they spend with their brother or sister per month (using all modes of contact), ranging from $1=$ less than $1-2 \mathrm{hr}$ per month to $5=10+\mathrm{br}$ per month. 
Independent variables. The independent variables included the brother or sister's activityemployment status (no activity vs. activitiesemployment) as well as variables found from Part 1 analyses to relate to the brother or sister not participating in any activities.

\section{Data Analysis}

Chi squares and Mann-Whitney $U$ tests were used to examine which characteristics of individuals with intellectual and developmental disabilities, the formal support system, and the familyinformal support system were associated with the absence of vocational-educational activities. Chi squares were used to test such categorical variables as specific condition or diagnosis (e.g., Down syndrome, autism), gender, and living status (living inside vs. outside of the family home). For ordinal or continuous variables such as brother/sister health problems, emotional-behavior problems, functional abilities, number of services, number of unmet services needed, or parent caregiving ability, Mann-Whitney $U$ tests were used. Because some variables were count variables and many of the distributions were not normal, we present nonparametric tests, medians, and quartiles (25th and 75th percentage) instead of the more conventional $t$ tests, means, and standard deviations. After running the bivariate tests, we tested for multicollinearity of the independent variables by examining their Variable Inflation Factors as well as the bivariate correlations between the independent variables. Those variables that did not have a multicollinearity problem were then included in a logistic regression equation to determine which independently predicted absence of activities.

Mann-Whitney $U$ tests were also used to examine the relations between the adult with intellectual and developmental disabilities' absence of activities and the sibling's positive wellbeing, depressive symptoms, health, affective closeness of the sibling relationship, and the amount of time the sibling spent with the brother/sister with intellectual and developmental disabilities. To determine whether the absence of activities served as an independent predictor of sibling outcomes, hierarchical ordinal regression models were examined. In the first step of each model, we entered activity status (absent vs. present) as the sole independent variable. In the second step, we added those characteristics of the brother/sister with intellectual and developmental disabilities, of the formal support system, and of the family-informal support system that had earlier been associated with the absence of activities for the brother or sister with intellectual and developmental disabilities. Because of the small amount of missing data $(<5 \%$ for any question), mean substitution was used following the guidelines of Harrell (2001).

\section{Results}

\section{Preliminary Analyses}

Nearly $13 \%(12.6 \% ; n=100)$ of sibling respondents indicated that their brother or sister with intellectual and developmental disabilities had no vocational or educational activities. The remaining $87.4 \%$ engaged in at least one activity. Most participated in a day activity program $(30.7 \%)$, followed by working in a supervised workshop $(28.1 \%)$. Nearly one quarter of the sample $(22.7 \%)$ worked in a paid job with assistance or with modifications, and $15.7 \%$ worked in a paid job in the community without supports. Almost one in seven adults with disabilities (13.8\%) was volunteering, and 5.0\% were in school, training for a future job, or in a prevocational setting (because adults with disabilities could participate in multiple activities, the sum exceeds 100\%).

\section{Part 1: Predictors of Lack of Activity for Adults With Intellectual and Developmental Disabilities}

As shown in Table 1, bivariate analyses revealed that lack of activity related to characteristics of adults themselves, the formal support system, and family-informal supports. Compared with those individuals who had regular jobs or activities, adults with intellectual and developmental disabilities who had no activities had much higher levels of emotional-behavioral and health problems and fewer functional abilities. When we examined emotional-behavioral problems, for example, the maximum possible level of emotional-behavioral problems was reported for $32.0 \%$ of adults with no activities compared with only $12.5 \%$ for those with jobs or activities, $\chi^{2}(1$, $N=796)=26.15, p<.001$. Similarly, whereas the maximum possible level of health problems was reported for $10.6 \%$ of those with jobs or daytime activities, such major health concerns 
Table 1

Bivariate Associations Between Absence or Presence of Vocational-Educational Activities and Characteristics of the Brother or Sister With Intellectual and Developmental Disabilities, Formal Supports, and FamilyInformal Supports

\begin{tabular}{|c|c|c|c|c|}
\hline \multirow[b]{2}{*}{ Variable } & \multicolumn{2}{|c|}{ Percents or medians (25th, 75 th quartiles) } & \multicolumn{2}{|r|}{ Test statistic } \\
\hline & $\begin{array}{l}\text { No activities } \\
(n=100)\end{array}$ & $\begin{array}{l}\text { Any activities } \\
(n=696)\end{array}$ & $\chi^{2}$ & $Z$ (Mann-Whitney $U$ ) \\
\hline \multicolumn{5}{|l|}{ Characteristics of brother or sister } \\
\hline Age (years) & $43.0(33.0,51.75)$ & $38.0(28.0,47.0)$ & & $-3.15 * *$ \\
\hline Female $(\%)$ & 42.0 & 42.2 & .00 & \\
\hline Down syndrome (\%) & 15.0 & 28.0 & $7.63 * *$ & \\
\hline Autism (\%) & 12.0 & 12.2 & .00 & \\
\hline Health problems & $3.0(2.0,4.75)$ & $3.0(1.0,3.0)$ & & $-3.89 * *$ \\
\hline Emotional/behavior problems & $3.0(2.0,5.0)$ & $2.0(1.0,3.0)$ & & $-4.38^{* *}$ \\
\hline Functional abilities & $40.5(31.0,48.0)$ & $44.0(34.1,52.0)$ & & $-2.84 * *$ \\
\hline \multicolumn{5}{|l|}{ Formal supports } \\
\hline Number of services received & $5.0(2.25,7.0)$ & $8.0(6.0,10.0)$ & & $-8.49 * *$ \\
\hline Unmet service needs & $3.0(1.0,6.75)$ & $1.0(0.0,2.0)$ & & $-7.37 * *$ \\
\hline \multicolumn{5}{|l|}{ Family-informal supports } \\
\hline Living at home $(\%)$ & 33.0 & 35.8 & 0.30 & \\
\hline Parents caregiving ability & $2.0(1.0,4.0)$ & $4.0(1.0,5.0)$ & & $-4.24 * *$ \\
\hline Female sibling (\%) & 76.0 & 80.9 & 1.32 & \\
\hline More than 2 in sibship (\%) & 77.0 & 78.0 & 0.05 & \\
\hline Sibling distance to brother/sister & $2.82(1.0,4.0)$ & $3.0(2.0,4.0)$ & & $-2.30^{*}$ \\
\hline
\end{tabular}

Note. Sibship $=$ number of children born to parents.

$* p<.05$. $* p<.01$.

occurred in $25.0 \%$ of those who had no jobs or activities, $\chi^{2}(1, N=796)=16.57, p<.001$. Those without (versus with) activities were also older and about half as likely to have Down syndrome; no differences emerged based on the gender of the adult with intellectual and developmental disabilities or whether that adult had an autism diagnosis.

Differences in activity status also related to formal and family-informal supports. Compared with adults who had regular activities, adults with no activities received a median of three fewer services and had two additional service needs. Stated differently, whereas high service needs (defined as needing three or more additional services) were noted for $23.0 \%$ of adults who had daytime activities, such high service needs were reported for $54.0 \%$ of the no-activity group, $\chi^{2}(1$, $N=796)=42.78, p<.001$. Similar differences were noted for family-informal supports. Adults who had no regular activities had parents with markedly lower caregiving abilities, and their sibling respondent lived closer. Thirty-five percent of parents of those with no activities were reported to have poor or fair caregiving ability compared with only $19.3 \%$ of parents of those with activities, $\chi^{2}(1, N=796)=12.97, p<.001$. No significant relations emerged between the absence-presence of activities and the residential arrangement (in or out of the parental home) of the adult with intellectual and developmental disabilities or with the number of siblings in the family.

Next, we conducted a logistic regression to determine which characteristics of the adults with intellectual and developmental disabilities independently predicted absence-presence of activities (Table 2). The Variable Inflation Factor for each independent variable was below 2.5 , indicating a low concern for multicollinearity. However, because the age of the adult with intellectual and developmental disabilities was correlated with nearly all of the other independent variables and particularly highly with parent caregiving ability $(r$ 
Table 2

Estimates From Logistic Regression Equation Examining the Independent Contribution of Characteristics of the Brother or Sister With Intellectual and Developmental Disabilities, Formal Supports, and FamilyInformal Supports in Predicting Absence of Vocational-Educational Activities

\begin{tabular}{lrlcc}
\hline \multicolumn{1}{c}{ Variable } & B & $\chi^{2}$ & Odds ratio (OR) & 95\% confidence interval for OR \\
\hline Characteristics of brother or sister & & & & \\
$\quad$ Female & -0.28 & 1.20 & 0.75 & $0.45-1.25$ \\
Down syndrome & -0.15 & 0.20 & 0.86 & $0.44-1.68$ \\
Autism & -0.30 & 0.55 & 0.74 & $0.33-1.64$ \\
Health problems & 0.25 & $6.41^{*}$ & 1.28 & $1.06-1.55$ \\
Emotional-behavior problems & 0.26 & $6.81^{* *}$ & 1.29 & $1.07-1.57$ \\
Functional abilities & -0.04 & $9.64^{* *}$ & 0.97 & $0.94-0.99$ \\
Formal supports & & & & $0.65-0.79$ \\
Number of services received & -0.34 & $46.08^{* *}$ & 0.72 & $1.03-1.24$ \\
$\quad$ Unmet service needs & 0.12 & $6.86^{* *}$ & 1.13 & \\
Family-informal supports & & & & $0.46-1.70$ \\
$\quad$ Living at home & -0.12 & 0.13 & 0.89 & $0.68-0.95$ \\
Parents caregiving ability & -0.22 & $6.83^{* *}$ & 0.80 & $0.20-0.66$ \\
Female sibling & -1.02 & $11.19^{* *}$ & 0.36 & $0.52-1.63$ \\
More than 2 in sibship & -0.09 & 0.09 & 0.92 & $0.65-0.96$ \\
Sibling distance to brother/sister & -0.24 & $5.56^{*}$ & 0.79 & \\
\hline
\end{tabular}

Note. Sibship = number of children born to parents. Age was removed from the logistic regression equation because of its high correlation with parent's caregiving ability.

$* p<.05 . * * p<.01$.

$=-.65)$, we did not include age in the logistic regression model. The overall model accounted for $19 \%$ of the variance in absence-presence of activities. All but one of the variables that were statistically significant in the bivariate analyses remained so, such that adults who had no activities had more emotional-behavioral and physical health problems, were lower functioning, received fewer services and had more service needs, had parents who were less able to provide care, and had siblings who lived closer to them. When combined with the other variables, Down syndrome diagnosis was no longer statistically significant. Alternatively, when combined with the other variables, the gender of the nondisabled sibling was statistically significant. Adults with intellectual and developmental disabilities were more likely to have no activities when they had male (as opposed to female) siblings.

\section{Part 2: Sibling Well-Being, Health, and the Sibling Relationship}

Our second research question examined the relations between the presence-absence of educa- tional or vocational activities and sibling wellbeing and health, as well as indexes of the sibling relationship. Descriptive statistics for the activity groups (no activities vs. any activities) and significance tests are presented in Table 3. Although no significant relations emerged between activity status and the sibling's positive well-being, those siblings whose brother or sister had no (vs. any) activities had higher depressive symptoms. Siblings whose brother or sister had no activities also reported worse health; among siblings of those with any activities, excellent health was reported by $29.2 \%$ compared with only $18 \%$ of siblings of those with no activities, $\chi^{2}(1, N=796)$ $=5.44, p<.05$. Compared with siblings whose brother or sister had any activities, siblings whose brother or sister had no activities also reported less affective closeness in the relationship. No significant relations emerged between absencepresence of activities and the amount of time siblings spent with their brother or sister with intellectual and developmental disabilities.

To determine whether presence-absence of activities was independently related to sibling 
Table 3

Bivariate Associations Between the Absence-Presence of Vocational-Educational Activities and Sibling WellBeing, Health, and the Sibling Relationship

\begin{tabular}{lccc}
\hline & \multicolumn{2}{c}{ Medians $(25$ th, 75th quartiles $)$} & $Z$ from \\
\cline { 2 - 3 } \multicolumn{1}{c}{ Variable } & No activities $(n=100)$ & Any activities $(n=696)$ & Mann-Whitney $U$ \\
\hline Sibling well-being & & & \\
$\quad$ Positive well-being & $86.19(76.0,93.75)$ & $89.0(80.0,95.0)$ & -1.60 \\
$\quad$ Depressive symptoms & $2.55(0.0,5.0)$ & $2.0(0.0,4.0)$ & $-2.37^{*}$ \\
Physical health & $4.0(3.0,4.0)$ & $4.0(3.0,5.0)$ & $-3.58^{* *}$ \\
Sibling relationship & & & \\
Affective closeness & $28.0(21.0,32.0)$ & $30.0(26.0,33.45)$ & $-3.43^{* *}$ \\
Time spent with brother/sister & $2.39(1.0,5.0)$ & $3.0(1.0,4.0)$ & -0.04 \\
\hline
\end{tabular}

$* p<.05 . * * p<.01$.

well-being and the sibling relationship, we next ran a series of ordinal logistic regression models. Our dependent variables were those sibling variables that were associated with presenceabsence of activities in the bivariate analyses (depressive symptoms, physical health, affective closeness). Our independent variables included presence-absence of activities, as well as those variables from Part 1 that were associated with the presence-absence of activities (health problems, emotional-behavioral problems, functional abilities, number of services, unmet needs, parent caregiving ability, sibling gender, and sibling distance to brother/sister). A two-part hierarchical regression model was thus run for each dependent variable. First, we entered into the regression the presence-absence of activities as the only independent variable. Second, we entered the aforementioned independent variables from Part 1, in addition to the brother/sister's presence-absence of activities.

As shown in Table 4, all three sibling measures (depression, health, affective closeness) were predicted by the presence or absence of sibling activity when entered alone. After controlling for characteristics of the individual with intellectual and developmental disabilities, formal supports, and family-informal supports, however, the absence of activities was no longer related to any of the three sibling measures. Instead, adverse sibling outcomes seemed more related to those same individual and support characteristics that increased the likelihood that the brother or sister lacked daytime activities in the first place. When brothers/sisters with intellectual and developmental disabilities had higher levels of emotional- behavioral problems, more unmet service needs, and compromised parental caregiving ability, then, they were more likely to have no daily activities, their adult siblings had worse health and mental health, and the two had less close sibling relationships.

\section{Discussion}

For adults with or without disabilities, a fulfilling adult life is associated with productive vocational and educational activities (Eliason \& Storrie, 2009; Eriksson et al., 2010; Hansen, 2005; Shepperdson, 1995). Many adults with intellectual and developmental disabilities do not have such regular daytime activities (Blackorby \& Wagner, 1996; Farley et al., 2009; Keogh et al., 2004; Wagner et al., 2005), yet few studies have focused on variables that predict their presence or absence. In the present study, we examined two aspects of this issue. First, we identified those characteristics of individuals with intellectual and developmental disabilities that might contribute to lack of activities; however, we also examined aspects of their formal and informal-familial supports. Second, we examined the relations between an absence of activities and the well-being and health of their adult siblings, as well as aspects of their sibling relationship. In addition to suggesting directions for future research, our results offer implications for practice and policy.

Consistent with prior studies, we found that characteristics of adults with intellectual and developmental disabilities related to the absence of vocational-educational activities. Similar to Esbensen et al. (2010) and Howlin et al. (2000), 
Table 4

Estimates From Hierarchical Ordinal Regression Models Examining the Independent Contribution of Presence-Absence of Vocational-Educational Activities in Predicting Depressive Symptoms, Physical Health, and Affective Closeness

\begin{tabular}{|c|c|c|c|c|c|c|}
\hline \multirow[b]{2}{*}{ Variable } & \multicolumn{2}{|c|}{ Depressive symptoms } & \multicolumn{2}{|c|}{ Physical health } & \multicolumn{2}{|c|}{ Affective closeness } \\
\hline & Model 1 & Model 2 & Model 1 & Model 2 & Model 1 & Model 2 \\
\hline No activity & $.49 * *$ & -.05 & $-.70 * *$ & -.32 & $-.70 * *$ & .02 \\
\hline Health problems & & $.11^{*}$ & & $-.12 *$ & & -.02 \\
\hline Emotional-behavior problems & & $.24 * *$ & & -.10 & & $-.45^{* *}$ \\
\hline Functional abilities & & -.00 & & -.00 & & $.02 * *$ \\
\hline Number of services & & -.02 & & .00 & & $.08 * *$ \\
\hline Unmet service needs & & $.08 * *$ & & -.02 & & $-.07^{*}$ \\
\hline Parents caregiving ability & & $-.10 * *$ & & $.21 * *$ & & .07 \\
\hline Female sibling & & .14 & & -.26 & & .27 \\
\hline Sibling distance to brother/sister & & -.08 & & .09 & & $-.18 * *$ \\
\hline$R^{2}$ & .01 & .10 & .02 & .10 & .02 & .19 \\
\hline
\end{tabular}

$* p<.05 . * p<p .01$.

who examined more general measures of adult outcome, protective factors promoting participation in daytime activities included fewer emotional-behavior problems and a diagnosis of Down syndrome (which no longer related after taking into account that adults with Down syndrome had fewer emotional-behavior problems). Individuals were also at greater risk for not having activities when they had fewer functional abilities and more health problems.

In addition to characteristics of the adults themselves, the absence of daytime activities was also predicted by formal and informal resources. With few exceptions (e.g., Esbensen et al., 2010), most adult-outcome studies do not include formal or informal supports as possible predictors measures. Yet in our study, services seemed critical: Greater numbers of received services and fewer unmet service needs both independently related to a greater likelihood of having any daytime activities. These differences were striking; the median number of unmet service needs for adults who participated in no activities was three times greater than those who engaged in any activity ( $3: 1$, respectively).

Therefore, a picture emerges of a particularly vulnerable subgroup of adults with intellectual and developmental disabilities. Those adults with intellectual and developmental disabilities who participated in no daytime activities were also more likely to show higher levels of behavioral, health, and functional problems; to be more underserved by the formal service system; and to have parents who were less able to adequately care for them. In this sense, the lack of any vocational or educational activity may itself constitute a marker for those adults with intellectual and developmental disabilities who are most in need of intervention and formal supports.

By addressing the needs of adults with intellectual and developmental disabilities who have no daytime activities, interventionists may also produce other beneficial effects. The adult siblings of these individuals, in particular, more often suffer from depressive symptoms, ill health, and less-than-optimal relationships with their brothers/sisters with disabilities. Although it is obviously important to help these adult siblings, there may also be implications for the broader society. Ultimately, inadequate systems of adult care pervade most American states (National Center for Family Support, 2000), as well as systems in most other countries (Emerson et al., 2007). As a result, we need adult siblings to assume high levels of caregiving for their brothers or sisters with intellectual and developmental disabilities when parents can no longer provide such care.

It is also important to consider the mechanisms underlying these effects on siblings. Specifically, the brother/sister's lack of activities did not appear to be driving these relations. Instead, the brother/sister's own lower functional abilities, greater levels of health and behavioral problems, fewer formal resources, and compromised parent 
caregiving led them to have no activities, and these factors-rather than inactivity of the brother or sister per se-then drove the sibling outcomes. Thus, interventions designed to address these factors among adults with intellectual and developmental disabilities might have a dual impact: increasing engagement in vocational and educational activities for adults with intellectual and developmental disabilities while promoting positive outcomes for the sibling and the sibling relationship.

This study also had several limitations that must be considered. First, although we examined a large national sample, the web-based format precluded full participation from siblings who were less educated, poorer, and from minority backgrounds. This study was also cross-sectional, which may have led to important cohort effects and made it impossible to separate out direction of effects. Thus, although we conceptualized the brother/sister's lack of activities as predicting the sibling relationship, less close sibling relationships might have led to a lack of activities for adults with intellectual and developmental disabilities. We also did not measure all possible predictors (e.g., poverty or other unmeasured predictors may have influenced brother/sister or sibling outcomes); our information about the activities of the adult with intellectual and developmental disabilities was reported by the sibling, and even our measure of "doing nothing" could have been inaccurate if, in a few cases, the person with intellectual and developmental disabilities participated in many leisure activities or events, even as they did not engage in any work, educational, or volunteer activities.

Even considering these limitations, however, this study offers important information for both practitioners and researchers. Given our relatively advantaged sample, the prevalence of adults with intellectual and developmental disabilities who have no educational of vocational activities is likely higher than the $12.6 \%$ found here. Those with no activities also had higher levels of physical and behavioral problems, fewer functional abilities, were underserved by the formal service system, and had parents who were less able to care for them. Their siblings, in turn, showed worse health, mental health, and sibling relationships, possibly affecting their own long-term caregiving. Ultimately, if we are going to help adults with disabilities (and their loved ones) live more fulfilling lives, we need to work harder to understand the character- istics and effects that occur when adults with disabilities are doing nothing.

\section{References}

Association of University Centers on Disability. (2011). [Web site]. Silver Spring, MD: Author. Available at: http://www.aucd.org

Bengston, V. L., \& Black, K. D. (1973). Intergenerational relations and continuities in socialization. In P. Baltes \& W. Schaie (Eds.), Lifespan development psychology: Personality and socialization (pp. 207-234). New York: Academic Press.

Blackorby, J., \& Wagner, M. (1996). Longitudinal postschool outcomes of youth with disabilities: Findings from the National Longitudinal Transition Study. Exceptional Children, 62, 399-413.

Braddock, D., Hemp, R., \& Rizzolo, M. K. (2008). The state of the states in developmental disabilities, 2008. Boulder, CO: Coleman Institute for Cognitive Disabilities and Department of Psychiatry, University of Colorado.

Caldwell, J. (2006). Consumer-directed supports: Economic, health, and social-outcomes for families. Mental Retardation, 44, 405-417.

Dykens, E. M. (2007). Psychiatric and behavioral disorders in persons with Down syndrome. Mental Retardation and Developmental Disabilities Research Reviewes, 13, 272-278.

Eliason, M., \& Storrie, D. (2009). Job loss is bad for your health: Swedish evidence on causespecific hospitalization following involuntary job loss. Social Science and Medicine, 68, 13961406.

Emerson, E., Fujiura, G. T., \& Hatton, C. (2007). International perspectives. In S. L. Odom, R. H. Horner, M. E. Snell, \& J. Blacher (Eds.), Handbook of developmental disabilities (pp. 593613). New York: Guilford.

Eriksson, T., Agerbo, E., Mortensen, P. B., \& Wesergaard-Nielson, N. (2010). Unemployment and mental disorders: Evidence from Danish panel data. International Journal of Mental Health, 39, 56-73.

Esbensen, A. J., Bishop, S., Seltzer, M. M., Greenberg, J. S., \& Taylor, J. L. (2010). Comparisons between individuals with autism spectrum disorders and individuals with Down syndrome in adulthood. American Journal on Intellectual and Developmental Disabilities, 115, 277-290. 
Farley, M. A., McMahon, W. M., Fombonne, R., Jenson, W. R., Miller, J. R., Gardner, M., ...Coon, H. (2009). Twenty-year outcome for individuals with autism and average or nearaverage cognitive abilities. Autism Research, 2, 109-118.

Golden Hills Software, Inc. (2011). Survey Gold [Software]. Retrieved November 29, 2011, from http://surveygold.com

Greenberg, J. S., Seltzer, M. M., Krauss, M. W., Chou, R. J.-A., \& Hong, J. (2004). The effect of quality of the relationship between mothers and adult children with schizophrenia, autism, or Down syndrome on maternal wellbeing: The mediating role of optimism. American Journal of Orthopsychiatry, 74, 14-25.

Hansen, H.-T. (2005). Unemployment and marital dissolution: A panel data study of Norway. European Sociological Review, 21, 135-148.

Harrell, F. E. (2001). Regression modeling strategies. New York: Springer.

Heller, T., \& Schindler, A. (2009). Family support interventions for families of adults with intellectual and developmental disabilities. International Review of Research in Mental Retardation, 37, 299-332.

Hodapp, R. M., Glidden, L. M., \& Kaiser, A. P. (2005). Siblings of persons with disabilities: Toward a research agenda. Mental Retardation, 43, 334-338.

Hodapp, R. M., Urbano, R. C. \& Burke, M. M. (2010). Adult female and male siblings of persons with disabilities: Findings from a national survey. Intellectual and Developmental Disabilities, 48, 52-62.

Howlin, P., Mawhood, L., \& Rutter, M. (2000). Autism and developmental receptive language disorder: A follow-up comparison in early adult life. II: Social, behavioural, and psychiatric outcomes. Journal of Child Psychology and Psychiatry, 41, 561-578.

Idler, E. L. \& Benjamini, Y. (1997). Self-rated health and mortality: A review of twentyseven community studies. Journal of Health and Social Behavior, 38, 21-37.

Keogh, B. K., Bernheimer, L. P., \& Guthrie, D. (2004). Children with developmental delays twenty years later: Where are they? How are they? American Journal on Mental Retardation, 109, 219-230.

McKee-Ryan, F. M., Song, Z., Wanberg, C. R., \& Kanicki, A. J. (2005). Psychological and physical well-being during unemployment:
A meta-analytic study. Journal of Applied Psychology, 90, 53-76.

Meyer, D. (n.d.). Sibling support project (Sibnet) [Web site]. Available at: http://www.siblingsupport.org/

National Center for Family Support. (2000, Winter). Aging family caregivers: Needs and policy concerns. Family Support Policy Brief. Tualatin, OR: National Center for Family Support, Human Services Research Institute.

Orsmond, G. I., \& Seltzer, M. M. (2000). Brothers and sisters of adults with mental retardation: Gendered nature of the sibling relationship. American Journal on Mental Retardation, 105, 486-508.

Powers, K., Hogansen, J., Genen, S., Powers, L. E., Gil-Kashiwabara, E. (2008). Gender matters in transition to adulthood: A survey study of adolescents with disabilities and their families. Psychology in the Schools, 45, 349-365.

Prouty, R. W., Smith, G., \& Lakin, K. C. (Eds.) (2006). Residential services for persons with developmental disabilities: Status and trends through 2005. Minneapolis: University of Minnesota, Research and Training Center on Community Living, Institute on Community Integration.

Radloff, L. S. (1977). The CES-D Scale: A selfreport depression scale for research in the general population. Applied Psychological Measures, 1, 385-401.

Ryff, C. D. (1989). Happiness is everything, or is it? Explorations on the meaning of psychological well-being. Journal of Personality and Social Psychology, 57, 1069-1081.

Seltzer, M. M. \& Li, L. W. (1996). The transitions of caregiving: Subjective and objective definitions. The Gerontologist, 36, 614-626.

Shepperdson, B. (1995). Two longitudinal studies of the abilities of people with Down's syndrome. Journal of Intellectual Disabilities Research, 39, 419-431.

Taylor J. L., \& Seltzer, M. M. (2010). Changes in the autism behavioral phenotype during the transition to adulthood. Journal of Autism and Developmental Disorders, 40, 1431-1446.

Taylor, J. L., \& Seltzer, M. M. (2011). Employment and post-secondary educational activities for young adults with autism spectrum disorders during the transition to adulthood. Journal of Autism and Developmental Disorders, 41, 556-574.

Wagner, M, Newman, L., Cameto, R., Garza, N., \& Levine, P. (2005, April). After high school: A first look at the postschool experiences of youth with 
disabilities: A report from the National Longitudinal Transition Study-2 (NLTS2). SRI Project P11182. Menlo Park, CA: SRI International.

Winkelmann, L., \& Winkelmann, R. (1998). Why are the unemployed so unhappy? Evidence from panel data. Economica, 65, 1-15.

Received 3/16/2011, accepted 9/6/2011.

Editor-in-Charge: Eric Emerson

We thank Mike Coburn, Sue Swenson, Elise McMillan, and the Board of Directors of The Arc for promoting this study. The members of the National Sibling Research Consortium were particularly belpful in designing this questionnaire; a special thank you goes to Marsha Mailick Seltzer, Gael Orsmond, Laraine Glidden, Carolyn Graff, Ann Kaiser, Ruth Roberts, Richard Urbano, and Elisabeth Dykens. This study was supported by a grant from The Arc as well as the Eunice Kennedy Shriver National Institute of Child Health and Human Development (Grant P30 HD15052 to E. M. Dykens [principal investigator]). We thank Richard Urbano for belp in managing survey responses.

Correspondence regarding this article should be sent to Julie Lounds Taylor, Vanderbilt Kennedy Center, 406a One Magnolia Circle, Peabody Mail Box 40-230 Appleton Pl., Nashville, TN 37203.E-mail: julie.l.taylor@ vanderbilt.edu 